\title{
From the ICELW 2010 Conference Chair
}

\author{
doi:10.3991/ijac.v3i3.1405
}

It has again been my pleasure to chair the International Conference on E-Learning in the Workplace (ICELW) in 2010. ICELW 2010 was our third annual conference, and I was pleased to see a continued increase in attendance and in the quality and size of the program. We also again had a large number of sessions that included demonstrations of e-learning work, as well as excellent keynote speakers, Tony O’Driscoll and Jonathon Levy, and a fascinating panel discussion led by Hal Christensen.

After a long period in which companies focused more on the management of learning than on learning itself, e-learning has been showing some signs of life in the past few years. We're seeing —and saw at ICELWnew and interesting uses of virtual worlds, a renewed interest in simulation-based learning, the growth of social learning, and the use of mobile devices for learning and performance support purposes.

As has often been the case over the years, we are at a time of great potential in workplace e-learning. Technology has people excited about the possibilities; the true progress in my mind, however, will be in the ways that we can design pedagogically-sound e-learning and usable, effective performance support products and methods. It can be all too easy for companies to embrace a new "learning technology" with too much emphasis on the technology and not enough on the learning. Through our work as researchers and/or practitioners in the field, we have the opportunity-and, from one perspective, the obligation--to create and study ways in which technology can best improve job performance.

I'd like to continue to view ICELW and iJAC as avenues through which we can advance the field in terms of both research and practice-providing academic researchers with real-world problems which can benefit from their research, and providing those in the world of corporate training with access to relevant research, both in the form of studies and by demonstrating new techniques in online learning and performance. Elearning in the corporate world is again at a stage of great opportunity, and both ICELW and iJAC have the opportunity to effect change.

I would like to thank all of our presenters and participants, as well as our Executive Committee, International Program Committee, keynote speakers, and our wonderful staff, for a great ICELW 2010, as we already look toward ICELW 2011, to be held in June 2011, again in New York. As always, I look forward to seeing continued work from iJAC and ICELW play a major role in influencing and improving the field of e-learning in the workplace.

\section{David Guralnick}

Chair, International Conference on E-Learning in the Workplace

Senior Editor, iJAC

President, International E-Learning Association

President, Kaleidoscope Learning 